\title{
GCU
}

Glasgow Caledonian

University

University for the Common Good

\section{A qualitative study of vaccination behaviour amongst female Polish migrants in Edinburgh, Scotland}

Gorman, D.R.; Bielecki, K.; Willocks, L.J.; Pollock, K.G.

Published in:

Vaccine

DOI:

10.1016/j.vaccine.2019.03.073

Publication date:

2019

Document Version

Author accepted manuscript

Link to publication in ResearchOnline

Citation for published version (Harvard):

Gorman, DR, Bielecki, K, Willocks, LJ \& Pollock, KG 2019, 'A qualitative study of vaccination behaviour amongst female Polish migrants in Edinburgh, Scotland', Vaccine, vol. 37, no. 20, pp. 2741-2747.

https://doi.org/10.1016/j.vaccine.2019.03.073

\section{General rights}

Copyright and moral rights for the publications made accessible in the public portal are retained by the authors and/or other copyright owners and it is a condition of accessing publications that users recognise and abide by the legal requirements associated with these rights.

Take down policy

If you believe that this document breaches copyright please view our takedown policy at https://edshare.gcu.ac.uk/id/eprint/5179 for details of how to contact us. 
A Qualitative Study of Vaccination Behaviour amongst Female Polish Migrants in Edinburgh, Scotland.

Gorman DR ${ }^{1^{*}}$, Bielecki K ${ }^{1}$, Willocks $\mathrm{LJ}^{1}$, Pollock KG ${ }^{2}$

1. NHS Lothian, Directorate of Public Health and Health Policy, Edinburgh, UK

2. School of Health and Life Sciences, Glasgow Caledonian University, Glasgow, UK

*Corresponding author: Dermot.Gorman@nhslothian.scot.nhs.uk, Public Health, 2-4 Waterloo Place, Edinburgh, EH1 3EG

Keywords: Hesitancy; Vaccine; Immunisation; Polish; Scotland; UK 


\begin{abstract}
Vaccine hesitancy is increasing and failure to vaccinate is well-recognised in Europe as a contributing factor to outbreaks of infectious diseases. In Lothian and Scotland, low vaccine uptake has been seen in migrants - notably in the Polish group who have arrived since 2004. The recent Vaccine Confidence in European Union report highlights a concerning recent decline in vaccine confidence in Poland.
\end{abstract}

We held three focus groups containing 13 Polish women about the childhood vaccination programme in Lothian, with specific focus on influenza and Human Papillomavirus vaccinations. Key emergent themes were: trust in the national vaccination policy, trust in the vaccination providers (health professionals), trust in the individual vaccines, balancing the risk of disease, and language and communication.

Polish norms, beliefs and behaviours shape how Polish migrants navigate the UK health system and its vaccination programme. While not confident in the Scottish primary care model and its generalist practitioners, the participants liked the ethos of informed consent in Scotland and compared this favourably with the compulsory vaccination policy in Poland. There was a belief that vaccines in Scotland were of higher quality than Poland and with fewer adverse effects.

Respondents reported returning to Poland for specialist clinical appointments and diagnostic testing. They regularly access Polish clinical expertise and their opinions about health are influenced by Polish friends and family. They say they have difficulty finding official UK Government and health authority vaccination material and often access Polish media, online resources and information., They are familiar with antivaccination activities in Poland.

Consequently, there are important unmet information needs for this group of parents who may not be making truly informed choices about vaccination. This requires further investigation especially as migration continues and declining immunisation uptake is reported in many countries across Europe. 


\section{Introduction}

Vaccination uptake varies greatly both between and within countries with differences noticed between socio-economic and ethnic groups (1-6). Typically, although not always, vaccine uptake is lower in less affluent groups, and ethnic minorities usually have lower uptake than native populations $(1,2,7)$. This has been extensively documented in Europe, including in the United Kingdom (UK) where South Asian and Chinese groups have been mostly studied $(1,8,9)$.

The views held about individual vaccination programmes can be variable and country specific - with opinions about, for example, influenza, Human Papilloma Virus (HPV) or childhood programmes varying between countries $(5,6,10)$. These opinions reflect the trust held in various aspects of the programme. Within the vaccination context Larson et al describe three levels of trust: in the product (the vaccine), the provider (those giving the vaccination), and the policy-makers (those approving and recommending the vaccination programme) (11).

Low vaccination levels are seen as an important health risk in the current refugee crisis and ECDC has highlighted fatal outbreaks of measles and other illnesses in European countries such as Romania, Italy, Greece, Germany, Ukraine and Poland $(6,12-16)$. There is little research about the vaccination behaviour of the European migrants who have arrived in the UK since the 2004 European Union (EU) expansion. In Scotland, the largest group of economic migrants is from Poland and National Records Scotland report that 99,000 Polish nationals now live in the country (17).

Although there is little literature regarding Polish migrants' vaccination behaviour, a previous analysis of H1N1 vaccination in pregnant Polish women living in Scotland highlighted "language problems", "difficulty accessing information", "concerns about vaccine safety and effectiveness", and "confidence in official Government advice" (18). Recent studies examining uptake by ethnicity in the school nasal influenza programme in Edinburgh and analysis of Scottish Human Papillomavirus (HPV) vaccination figures in girls were stimulated by an observation of low uptake in schools with large migrant pupil groups $(19,20)$. In 2017 , nasal influenza vaccine uptake was only $25.0 \%$ in Polish children, compared to $70.7 \%$ in White British and $60.9 \%$ in other identified ethnic minorities. Notably, the school influenza programme had a high parental refusal rate by Polish parents (36.8\%) compared to British and other minorities $(6.2 \%$ and $7.3 \%)(20)$. Low uptake of the HPV vaccine in Polish school children in Scotland was shown with a significant disparity between Polish $(72.0 \%)$ and British $(89.8 \%)$ children's completed HPV vaccine uptake rates in 2016/17 (19). The vaccination programme in Poland has higher uptake for routine childhood immunisations than the UK, but has lower uptake for HPV and influenza (4, 21-24). In Poland childhood vaccinations are compulsory, but HPV and influenza are both merely recommended, and unlike Scotland, there is no school influenza programme for healthy children (25). 
The recent important EU report 'State of vaccine confidence in the EU 2018' highlighted that Poland has experienced the largest decrease in vaccine confidence in EU between 2015 and 2018 (6). In Poland, there has been a gradual rise in vaccine refusals (increasing over 400\% between 2007 and 2016) and uptake of childhood immunisations is slowly declining (26). This is illustrated by the uptake of the first dose of the Mumps Measles and Rubella (MMR) vaccine decreasing from 98.3\% to 95.5\% in 2016 (26-28). ECDC highlights 'notable increases' in measles cases in Poland in November 2018 (16) and the EU report notes low confidence in the MMR vaccine in the country (6). This could result in extensive measles outbreaks, such as experienced in neighbouring Ukraine (12) and the large number of Ukrainian migrants to Poland amplifies this risk (29). The drop in vaccination uptake can be partially attributed to anti-vaccination campaigners who have a prominent presence in the Polish media. Consequently vaccine hesitancy is being increasingly addressed by Polish researchers $(6,28,30)$.

NHS Lothian (the NHS Region serving Edinburgh and three adjoining council areas with a population of almost 900,000 ) has experienced slowly decreasing vaccine uptake in several programmes in recent years. Investigation has shown evidence of reduced uptake in the Polish community, accompanied by many anecdotal reports of Polish migrants asking NHS staff unusual questions about the vaccination programme indicating their uncertainty and concern (LW personal communication).

The aim of this study is to explore Polish migrant women's views on the childhood vaccination programme in Edinburgh, Scotland, in the context of the trust held in various aspects of the programme and with a specific focus on influenza and HPV vaccination.

\section{Methods}

\section{Study Setting and Population}

The 2011 Census shows Lothian has been an important destination for Polish migrants, and extrapolation from this suggests that over 28,000 now live in the region. There are over 700 babies born in Lothian to Polish mothers each year and the Polish community in Scotland is young with many families with children (31). Community development projects have become established and help migrants integrate into Scottish society and navigate health and social care services. Two such organisations assisted this evaluation of service uptake by hosting focus groups of Polish parents and grandparents.

The study comprised three focus group interviews conducted in Edinburgh, Scotland with Polish caregivers. NHS Lothian has ongoing links with community health projects with Polish services in Edinburgh, often consulting with them on health con- 
cerns (e.g. on cancer screening and mental health issues REFS??). These health projects run social events and hold themed groups (e.g. mother and toddler) for the Polish population in Edinburgh. A consultant (DG) and Polish-speaking researcher (KB) contacted two of their Polish link workers to ask about vaccination issues and they offered to facilitate focus groups on the subject. Two groups were held of the regular attenders of a mother and toddlers' group, with a third group recruited opportunistically by the link worker from community health project users.). Refreshments were provided and bus fares were refunded, but no other incentive was offered. Each focus group lasted between 45 and 90 minutes

An information sheet accompanied a consent form and emphasised confidentiality, that our study was seeking views about the Polish community not just individual opinion and that all views were welcome and valued.

\section{Ethics}

The evaluation was discussed with the Research Ethics Scientific Co-ordinator who confirmed in writing that as this was a service evaluation formal ethical approval was not required. Best research practice was employed with each participant receiving a paper copy of the informed consent, in English and Polish, prior to the focus group. The participants were given time to read over the information and an opportunity to discuss the information sheet with the interviewer before the focus group took place.

\section{Data Collection}

A topic guide was used to lead discussion and allowed flexibility in conversation to express and elaborate on the participants' thoughts to encourage production of a wide breadth of data. It was developed following a literature review and discussions with local Polish health workers to identify areas of interest $(2,3,32$, 33). Topics included: general views about healthcare and experience of vaccination in Poland and Scotland; sources of information about vaccination; vaccine safety and exposure to anti-vaccination messages or sentiment; risks posed by infectious diseases and the relevance and availability of NHS produced information.

The focus groups were conducted in Polish in March 2018, by a bilingual female public health researcher (KB) and recorded. Recordings were transcribed into Polish and then translated into English by the NHS Lothian interpretation and translation service.

\section{Analysis}

We used a thematic analysis method whereby two authors (KB \& DG) conducted an initial scan of the transcripts for emerging themes (e.g. autism, health service general, vaccine fears). All authors reviewed the translated transcripts independently, and then met in face-to-face and virtual meetings to refine the themes, and agreed the central themes from the analysis. These are: 
- Trust in the national vaccination policy

- Trust in the vaccination providers (health professionals)

- Trust in the individual vaccines

- Language and communication

- Balancing the risk of disease

\section{Results}

Our group comprised 13 female participants: one was in her late 20s, nine in their 30 s, one in her 40s and two over 60, who were grandmothers to young children (and attended with their own daughters who were themselves parents of young children). Demographic details of presented in Table 1.

Table 1: Demographic details of participants

\begin{tabular}{|l|l|}
\hline & $\begin{array}{l}\text { Total } \\
(\mathrm{N}=13)\end{array}$ \\
\hline Age (\%) & \\
\hline $18-29$ & 1 \\
\hline $30-44$ & 10 \\
\hline $45-59$ & 0 \\
\hline $60+$ & 2 \\
\hline Educational Qualifications (\%) & \\
\hline High School Qualification & 6 \\
\hline Some College/Associates Degree/NVQ & 3 \\
\hline Bachelor's Degree or higher & 4 \\
\hline Number of children (\%) & \\
\hline 1 & 8 \\
\hline 2 & 3 \\
\hline 3 & 2 \\
\hline Length of Residency in Scotland (\%) & \\
\hline $2-5$ Years & 3 \\
\hline
\end{tabular}




\begin{tabular}{|l|l|}
\hline $6-10$ Years & 6 \\
\hline $11-15$ Years & 3 \\
\hline Unrecorded & 1 \\
\hline
\end{tabular}

\section{Trust in the national vaccine policy}

The participants used the Polish system as a benchmark, and differences in Scottish healthcare and vaccination policy were recognised. However, the differences in vaccination policies and schedules were not viewed as a problem by our participants. Instead, the women spoke of taking a pragmatic approach, that children born and living in Scotland are vaccinated there. Several parents stated that they complied with NHS invitations without being clear which vaccinations had been given to their children.

"I must admit that I do not really know what my children are immunized for, because I didn't check what the vaccines were, I simply just went, trusted and vaccinated. Maybe - if something bad happened, I would have given more thought..." Participant I (mother, 28 years old, child vaccinated)

"There are different vaccination calendars, but we vaccinated all our children in the UK... I did not think twice about there being a Polish calendar." Participant K (mother, 28 years old, child vaccinated)

The respondents reported dissatisfaction in the Polish community with the NHS's lack of flexibility to customise vaccinations for individual children. While the basic provision of the Scottish vaccination programme is deemed acceptable, women expressed some desire to supplement the routine Scottish programme with additional vaccinations that are offered in Poland. The participants recognised that Bacillus Calmette-Guerin (BCG) vaccination wasn't offered to Polish children born in Scotland but was mandatory in the Polish vaccination programme. One woman mentioned that children were being taken to Poland for vaccination - this view was not opposed but only one women shared that she had her child vaccinated in Poland (against tuberculosis. There was widespread recognition within the group that parents could independently choose whether to vaccinate their child in Scotland, and that this Scottish culture of 'informed consent' and free choice was distinctly different to the Polish Government's rules and potential sanctions about compulsory vaccination:

"It is strange that if I want to the NHS won't let me give vaccinations in instalments...I would like to spread [the vaccinations] out into smaller steps." Participant $\mathrm{C}$ (mother, 30 years old, child not vaccinated) 
"There is a group of people who do not completely trust the health service and get treatment in Poland...mothers are taking children to Poland to vaccinate, because they do not trust vaccines here." Participant I (mother, 30 years old, child vaccinated)

"I bought this vaccine separately because the GP said that they do not vaccinate for tuberculosis... I would prefer that she had this vaccine. Well, we just bought this vaccine ourselves... it wasn't very expensive." Participant $\mathrm{C}$ (mother, 30 years old, child not vaccinated)

"Well...I have not heard about the trend for non-vaccinating, because in Poland, as far as I know, they can legally take your child if you do not vaccinate. Or you can go to prison ... So there is a much better system here than in Poland, really." Participant $L$ (mother, 35 years old, child not vaccinated)

The benefits of the free vaccination programme in Scotland were noted. Two mothers reported their experience in Poland of buying expensive combination vaccines to avoid several injections necessary in the Polish state-funded programme.

"I paid for all of the vaccines in Poland, because with the free ones they would stab her five times with five different bacteria. And so I paid extra to have the five-in-one, like the one they are giving in this country for free." Participant $\mathrm{C}$ (mother, 30 years old, child not vaccinated)

"In Poland... I remember, for all vaccines, it amounted to over a thousand zlotys (£205 approximately). "It was so very expensive... but here they are for free... in Poland, you pay big money." Participant M (mother, 26 years old, child vaccinated)

\section{Trust in the vaccination providers (health professionals)}

Vaccinations in Poland are supervised by doctors - mainly general practitioners or less commonly paediatricians and delivered by qualified nurses from vaccination units. Children are examined pre-vaccination by a physician and will not be offered vaccination if they have fever or other symptoms of infection. In Scotland, general practitioners (GPs) supervise vaccinations which are given by nursing staff. Primary care management of patients with a team-based approach and clinical information shared amongst members is the norm in Scotland. Some of our participants viewed this as being risky to patients, due to lack of continuity of care and perceived lack of qualifications and expertise in staff groups. Our participants expressed concern about the training and individual expertise of GPs. They doubted the GP generalist providing what they see as a specialist service. One mother noted happily spending money on international telephone calls to Poland to seek and be reassured by Polish medical opinion (via her own mother). 
"Here, everyone goes to the same doctor who sees everything - ad hoc they even pretend to be a gynaecologist and all the rest, right?" Participant $F$ (grandmother, 82 years old, children vaccinated)

"I'm trying to trust the doctors here...sometimes when I go to GP and when he is Googling...I laugh a little bit, because I could have done that myself at home." Participant $\mathrm{D}$ (mother, 35 years old, children vaccinated)

"I sometimes call Poland: "Mama, ask our family doctor this and that...I prefer to call; I've spent two or three pounds calling Poland, but at least I'II find out, right?" Participant B (mother, 30 years old, children vaccinated)

Respondents consistently compared the expertise of the main vaccination staff groups, favouring the medical input of Poland to the Health Visitor (nurse) in Scotland. There were multiple reservations expressed about the validity and usefulness of Health Visitors' advice.

"The reason why parents are questioning the vaccination here is that there is paediatrician in the clinic...in Poland - you see the child's doctor... he a specialist in children, so you have more confidence..." Participant E (grandmother, 80 years old, children vaccinated)

"Every time when I go to the GP it's a different person... these vaccinations are given by nurses, it's so very impersonal and if there's some reaction then you go to the hospital, right? ... at the GP they will not notice something is happening with the child...it seems to me that there should be a doctor, just one person who would be connected with the child." Participant $L$ (mother, 35 years old, child not vaccinated)

"Here they do not encourage you so much ... The health visitor will come, yes, this is her job, and she has to give me a pile of documents that she will present to me, right? Well, this is her job, that's what she's paid for...but the health visitor is not a doctor who will convince us." Participant $\mathrm{C}$ (mother, 30 years old, child not vaccinated)

"I suspect that the health visitor here ... they are not trained about side effects. I suspect that they do not even know what these vaccinations are for, they only give you a book and read what they have on the pages to read...if I probably asked what the vaccine is and benefits will it do in my child's body, I suspect that she probably would not know." Participant D (mother, 35 years old, children vaccinated)

There was concern that vaccination provision in Scotland does not include children being examined pre-immunisation by health staff, and that children with a cough or cold may be vaccinated. 
"I do not like that the doctor [in UK] does not examine the child before vaccination... I strongly asked for him to be auscultated when he was last vaccinated. They were a little surprised that I insisted on it." Participant A (mother, 25 years old, children vaccinated)

Counteracting the general scepticism about GPs, one woman contradicts the commonly held view that Polish patents want investigations and medication and was appreciative of the UK approach of limiting antibiotics and suggesting paracetamol. Another woman also expressed confidence in the advice of her Midwife.

"I like the NHS approach - they do not give out as many antibiotics as in Poland. In Poland, I spent my entire childhood on antibiotics, whatever the problem was - the answer was antibiotics. And here, with the paracetamol, actually it seems to me that it works... like that there is a more natural approach than in Poland." Participant L (mother, 35 years old, child not vaccinated)

"I first came across vaccinations during pregnancy in the UK. But I went to the advice of my midwife, and she told me that everybody is actually inoculating, that it is for the child's sake in childbirth, right? And that convinced me." Participant $\mathrm{J}$ (mother, 38 years old, child vaccinated)

\section{Trust in the individual vaccines (product)}

Our Polish participants reported negotiating their child's immunisation schedule with their own doctor in Poland. They considered both timing of vaccinations, and significantly, also the actual vaccines offered (including the vaccine manufacturer or brand, and specific preservatives and antigens contained in the vaccine). There was speculation from our participants about the differences in the composition of vaccines used in each country. There was a common belief (although not uniform) that Polish statefunded vaccines were somehow inferior to those in the UK, and thus caused more side effects. One woman believed that Polish people actually really thought vaccines were safe, but expressed concerns about their safety as a pretext for not vaccinating their children.

"There is no choice here, it is the first class stuff, and in Poland there is the second quality grade, which is free...from what I've heard that the vaccines in Poland are worse - kind of dirty, polluted. That's why more complications happen in Poland than here." Participant K (mother, 28 years old, child vaccinated)

"I do not really have much trust in the vaccines in Poland...too many people have problems with them...I would be so scared to vaccinate in Here, more than once, I heard 'I was vaccinated in Poland and my child suddenly had autism."' Participant B (mother, 30 years old, children vaccinated) 
"I don't think Poles think vaccines are unsafe...but they just look for arguments against vaccination..." Participant $\mathrm{M}$ (mother, 26 years old, child vaccinated)

The combinations of antigens that vaccines now contain were compared to those the parents experienced when they were children in Poland pre-migration.

"In my opinion, the children get colossal doses now, right? Now, there are seven vaccines in one, well, people, well, why the hell...We were all vaccinated, but no one got the large doses that the children get now. And it's no surprise that later on a child who has weak immunity gets ill, when they get such a dose at once..." Participant C (mother, 30 years old, child not vaccinated)

HPV was specifically commented upon. "Oh no! Absolutely not [HPV]! I've heard about girls who have had paralysis after these vaccinations, I've heard about many, many cases, I do not think it's made up and I would absolutely not agree." Participant $L$ (mother, 35 years old, child not vaccinated)

\section{Communication}

Challenges due to language and operating in an English-language medical culture were universally raised. Respondents said Polish language information was difficult to find, and if found, it was hard to understand. One noted their access to GP care was compromised by lack of an interpreter.

"I'm just learning English, right? I'm not sure, I do not know medical terms...so I call the doctor, and the receptionist said to me: 'No, we cannot accept you today with your child, because we do not have translators available'." Participant C (mother, 30 years old, child not vaccinated)

"It's hard for me...because you have to beg for information... Yet, if you ask for it, they will give it to you in a way that you will not understand it because there is very little information and it is covered in footnotes." Participant B (mother, 30 years old, children vaccinated)

"I know there is information in the NHS, because there are some leaflets you can get there... But it wasn't so with vaccinations - no. I did not get anything even in English." Participant D (mother, 35 years old, children vaccinated)

Women described the strategies they used to obtain information - citing friends, and the Internet, with specific examples of using Google Translate, Facebook, and Wikipedia. One noted potential shortcomings with internet-sourced information and others complained that NHS information did not cover information about 'vaccination problems' or cite statistics. 
"Everything I was given was in English. I did not get anything in Polish. I need to run everything through Google translator, and translate everything myself if I don't understand something." Participant C (mother, 30 years old, child not vaccinated)

"Really, at the beginning I went to the NHS website, but I realized that there is not a lot of information there. In addition, there is no information about cases of these problems and no cited statistics at all." Participant $L$ (mother, 35 years old, child not vaccinated)

"I received very little information here about long-term complications. Short-term side effects yes, like about how that fever can happen... However, nobody talks about complications in two or three years." Participant $\mathrm{G}$ (mother, 38 years old, child vaccinated)

The activities of anti-vaccination groups and that these might influence vaccination choices were recognised by all our participants. However, only two of the mothers had not vaccinated their children. One parent did made a link between an older child's vaccination and later diagnosis of autism as a reason for not having her younger child vaccinated.

"In Poland, it has become more fashionable not to vaccinate, with the publicity of celebrities talking about not vaccinating..." Participant A (mother, 25 years old, child vaccinated)

"I vaccinated because we got an invitation each time my daughter was due an immunisation -we just went... It was only after we got vaccinated that I heard that there could be complications and that in Poland it is not so popular to vaccinate." Participant $\mathrm{J}$ (mother, 38 years old, child vaccinated)

"You just often hear that vaccination causes autism. And so...I risked it since we were vaccinated when we were young and nothing really happened to us." Participant D (mother, 35 years old, children vaccinated)

\section{Balancing the risk of disease}

Given the age profile of our participants, vaccinations during pregnancy were topical. Many respondents noted concerns about the maternal influenza programme in Scotland which they deemed unnecessary. This was generally because they were fit and well, but also reflects the fact that vaccinations are not recommended in pregnancy in Poland. HPV was also controversial with some knowledge of the issues experienced in Japan and Ireland $(34,35)$.

"When I was pregnant, I was recommended the flu shot but... absolutely no, I do not see the need, I do not get sick myself... I think I see that chil- 
dren who are vaccinated are more ill than those what is unvaccinated. There is a lot of opinion that even if you get vaccinated for flu, you can get sick anyway, so it is not so necessary for me..." Participant L (mother, 35 years old, child not vaccinated)

"I do not believe in flu vaccination, because flu every time it mutates, it's different, so I came to the conclusion that the pregnancy itself is an extraordinary burden on the body and so why provoke it even more. So I gave up flu vaccination, although it was recommended." Participant $\mathrm{K}$ (mother, 28 years old, child vaccinated)

"I must admit that I am not vaccinating my daughter for the flu because she is seven years old and somehow she never gets sick... And somehow I am not comfortable because at school they give these vaccines into the nose." Participant $\mathrm{D}$ (mother, 35 years old, children vaccinated)

"Especially since the smear test here is only every three years, and the period of sexual initiation keeps getting younger ... If I had the opportunity, I would have vaccinated myself for [HPV]." M30

"I visited Edinburgh before we moved... I saw the colourful world of people here, and it made me think: "Damn, there must be so many diseases you have not even dreamed of here!"... So I vaccinated, because it is known, that every nationality brings its own bacteria and viruses and you have to somehow immunize against them." Participant $\mathrm{F}$ (grandmother, 82 years old, children vaccinated)

\section{Discussion}

This is one of the first qualitative studies asking European migrants about their experience of the routine child and maternal vaccination programme in Scotland. Our focus groups report on both the participants' own personally held views and more widely about 'Polish people in Scotland'. Our results suggest that when considering vaccination, Polish migrants in Scotland constantly compare the service offered in Scotland with those they would expect at 'home' in Poland. Their opinions are largely shaped by their experience and general impressions of the Scottish health service, not just vaccination provision. Our participants did not suggest that dual-use of vaccination services was a common feature of Polish people living in Scotland, but clearly demonstrated that their behaviour is influenced by Polish norms and contact with Polish sources, including practitioners, family or friends and information from Poland.

\section{Trust in the policymakers $\&$ vaccination providers}


Participants' trust is high in the government-provided vaccination programme in UK and this was praised for being free and of high quality. Participants claimed to be able to differentiate between vaccine qualities in each country and expressed a clear concept of 'good' and 'bad' vaccines, with a notion expressed that vaccines in Scotland are more modern and speculation that adverse reactions were more common in Poland.

Poland's vaccination schedule is very similar to that in the UK. Most vaccinations are provided free by the state and are compulsory with immunisation uptake policed by Sanitary Inspectors with parents (at least theoretically) liable to fines should children be unimmunised (26). Some vaccines, such as against rotavirus and HPV, are "recommended" by the Polish authorities but paid for by families, with for instance complete HPV vaccination costing approximately $30 \%-50 \%$ of the average Polish monthly salary (M. Ganczak, personal communication). There is a wide range of vaccines with different combinations of antigens marketed by different companies and suppliers. We think the question of exactly just 'which vaccine should my child have' is thus part of the complex conversation between healthcare staff and parents in Poland. The end result is that in Poland families are able to negotiate variation around the margins of the programme. This means that children often have a bespoke schedule which is influenced by parental desires and ability to pay and overseen by a physician. In Scotland the overwhelming majority of children get the same free government-provided vaccines. This, we suggest, means Polish parents in the UK may, as they would in Poland, seek a technical discussion about vaccines with healthcare staff as they assess the risk of their choices. When they ask such questions to Scottish healthcare staff, they may not get what they regard as a satisfactory and expert answer - serving to undermine their trust in the Scottish system.

Migrants are unfamiliar with the roles of UK healthcare staff groups, such as Health Visitors and Community Midwives. They are not used to the UK primary care system, and can become irritated by being unable to make appointments with NHS specialists directly (36-39). The Polish migrants we interviewed have concerns about the lack of paediatric specialist input within the child vaccination clinical pathway. In Poland, the doctor would always examine children prior to immunisation - something that respondents report does not happen in Scotland. This lack of "hands-on" and "continuous care" is regarded as unsatisfactory.

Poland was later than the UK to update its vaccination schedule and introduce newer vaccines, for instance, introducing MMR in 2004 compared to 1988 in the UK (40, 41). A 2011 paper commented that Poland was still using vaccines that contain thiomersal 'owing to economical reasons' (42). These factors could lead to Polish people thinking their system is old-fashioned and not as good as Scotland's. As in the UK, parents in Poland find healthcare workers and doctors in particular as the most credible and desirable source of information (43). Several respondents mentioned paying 
for multi-antigen vaccines in Poland in preference to the state-provided versions with the main motivation being to inflict fewer injections on their child.

The fact that influenza and pertussis vaccine are offered during pregnancy in Scotland but not in Poland may also reinforce an impression that Poland's system is behind other countries. However, new vaccines are often perceived as potentially more risky and respondents explain that as they previously had healthy babies without these vaccinations, they do not believe them necessary. There are also commonly held views among our participants that influenza is a relatively mild illness, while the vaccine is of doubtful effectiveness and that vaccination could even cause illness. As mentioned above, Poland is generally less positive about influenza vaccination than other European countries $(6,44)$. The Polish vaccination calendar also still immunises against tuberculosis, a topical issue in Poland, which is experiencing immigration from countries with much higher tuberculosis prevalence. It was interesting that one woman noted the multicultural aspect of Edinburgh and assessed the risk of infectious disease to be higher, in turn prompting her to be more positive about vaccination for her child.

\section{Language}

The language barrier is clearly an issue for our participants with difficulties communicating with practitioners and accessing written information. Although NHS Scotland produces translated versions of vaccination materials, our participants were unaware of and did not access these materials. This finding concurs with previous research about pandemic swine flu vaccination in Scotland (18). Respondents thus rely heavily on Polish sources for information about vaccines and vaccination, typically from Polish family, friends, media, social media and internet sites.

This means they are unlikely to read or learn the reasoning behind the Scottish vaccination programme, and will increase the likelihood of their accessing confusing, incorrect or biased information. Vaccination in Poland is described in the EU report as having 'lack of strong government support', with doctors and parliamentarians active in the anti-vaccination movement. The STOP-NOP anti-vaccination movement is large and active in Poland for instance organising petitions and demonstrations against mandatory vaccinations $(6,45)$. It uses social media and populist approaches to emphasise the fact that the compulsory system is a relic from the discredited Communist days, and scaremongers about the increasing number of vaccinations and multi-dose combinations children are presently compulsorily receiving (46). The fact that respondents access Polish source information, combined with the powerful anti-vaccination movement will certainly mean that Polish migrants in Scotland are exposed to negative messages about vaccination. In Poland, the National Sanitary Inspection service notes that $23 \%$ of non-immunising parents are influenced by the anti-vaccination movement (6). A consequence of this is that it seems unlikely that Polish people in Scotland are, with their current sources of information, making truly informed decisions about vaccination. This lack of informed consent is at odds with 
our participants' sense that the opt-in nature of the Scottish programme is one of its advantages.

\section{Study Limitations}

The study of vaccine hesitancy is a relatively new field. Research increasingly highlights the complexity of issues involved and the nuances between vaccination programmes country by country. The 13 participants in our focus groups represented 11 families and were recruited opportunistically through their connections with recognised Polish health project groups. Their demographics (young families with associated grandparents) are typical of Polish migrants to Scotland but as service users they could be more 'health conscious' than Polish migrants in general. They described vaccination in a sophisticated and segmented manner, and having to navigate the system while taking into account a mixture of common considerations about vaccination and specific issues with each vaccination programme. There would be benefit in both holding more focus groups to achieve saturation, as well as segmenting the topic guides to focus on one vaccination programme at a time. In some circumstances focus groups with people who have accepted or refused a particular vaccine or individual interviews where sensitive topics, such as autism, are discussed may be more appropriate. Opinions expressed on our focus groups could be quite forthright and scientifically incorrect, meaning that counter-views might, despite the best efforts of facilitators, be stifled in the group setting.

Having a Polish-speaking researcher was beneficial for organising and facilitating the focus groups, as well as being able to converse with Polish academics and draw on experience from her own background in Poland and Canada. The research group have been previously studying Polish migrant healthcare, but made considerable efforts to abandon any preconceived ideas about the data and truly let the themes emerge from the data. The researcher $(\mathrm{KB})$ and the facilitators of the focus groups do not have specialist vaccination expertise. The first author (DG) was present during the focus groups but in the background and available to answer specific concerns if these arose amongst the participants. Participants were not directly asked about their own vaccination choices and the focus group facilitators adopted a nonjudgemental and neutral stance to any disclosures and were clear that they were not promoting a 'NHS agenda'.

\section{Recommendations and Further Research}

It seems important that the NHS develops improved information material about vaccination to educate both patients and staff, which considers the reality of dual-use of healthcare in two countries by migrants, and how migrant children are assimilated into the Scottish system.

Findings of the work have already led to the revision of the Polish language childhood influenza programme information booklet to include detail about the Scottish 
vaccination programme and why it is different to Poland (e.g. by not having BCG immunisation and having the school influenza programme). Nonetheless, this is just one change and uses a traditional leaflet approach. Further thought is required into use of web-based education and social media, as well as recruiting key opinionformers in the Polish community in Scotland, such as the Polish doctors working in Lothian as allies. Efforts must extend to more than just booklets, and include staff training, for example preparing Health Visitors with answers to frequently asked questions posed by migrants.

We show that Polish migrants retain Polish norms and opinions about vaccination and suggest that these play a central role in their vaccination decision-making. They, as British people, trust the vaccination programme while having concerns about side-effects and particular vaccines. There are predictable language related issues and these is also concern about the roles and expertise of unfamiliar staff groups.

This transnational transfer of behaviour is important especially considering that vaccination confidence is 'rapidly declining' in Poland (6) at the same time as there are increases in measles and other infectious diseases in Europe.

\section{Competing Interests}

The Authors have declared that no competing interests exist.

\section{Acknowledgements}

The authors would like to thank all the women who took part in the study; colleagues at Health All Round (http://www.healthallround.org.uk) and at Feniks (http://www.feniks.org.uk) for hosting us at the community health project meetings and assisting in the organization of the focus groups; the Polish translator team for their transcription and translation work; Martin Higgins for his editing guidance; $\mathrm{Dr}$ Anna Cunningham, Dr Carol Gray Brunton, and Judith Sim for their advice on qualitative analysis and write-up.

\section{References}

1. Forster AS, Rockliffe L, Chorley AJ, Marlow LAV, Bedford H, Smith SG, et al. Ethnicity-specific factors influencing childhood immunisation decisions among Black and Asian Minority Ethnic groups in the UK: a systematic review of qualitative research. Journal of Epidemiology and Community Health. 2016;71(6):544-9. 
2. Fournet N, Mollema L, Ruijs WL, Harmsen IA, Keck F, Durand JY, et al. Undervaccinated groups in Europe and their beliefs, attitudes and reasons for nonvaccination; two systematic reviews. BMC public health. 2018;18(1):196.

3. Dubé E, Gagnon D, Nickels E, Jeram S, Schuster M. Mapping vaccine hesitancy-Country-specific characteristics of a global phenomenon. Vaccine. 2014;32(49):6649-54.

4. Jorgensen P, Mereckiene J, Cotter S, Johansen K, Tsolova S, Brown C. How close are countries of the WHO European Region to achieving the goal of vaccinating $75 \%$ of key risk groups against influenza? Results from national surveys on seasonal influenza vaccination programmes, $2008 / 2009$ to $2014 / 2015$. Vaccine. 2018;36(4):442-52.

5. Kanitz E, A Wu L, Giambi C, Strikas R, Levy-Bruhl D, Stefanoff P, et al. Variation in adult vaccination policies across Europe: An overview from VENICE network on vaccine recommendations, funding and coverage. Vaccine. 2012;30(35):5222-8.

6. Larson $\mathrm{H}$, de Figueiredo A, Karafillakis $\mathrm{E}$, Rawal M. State of vaccine confidence in the EU 2018. Luxembourg: Publications Office of the European Union; 2018.

7. Public Health England. Prenatal pertussis immunisation programme 2014/15: Annual vaccine coverage report for England. London; 2015.

8. Mixer RE, Jamrozik K, Newsom D. Ethnicity as a correlate of the uptake of the first dose of mumps, measles and rubella vaccine. Journal of Epidemiology and Community Health. 2007;61(9):797-801.

9. Donaldson B, Jain P, Holder BS, Lindsey B, Regan L, Kampmann B. What determines uptake of pertussis vaccine in pregnancy? A cross sectional survey in an ethnically diverse population of pregnant women in London. Vaccine. 2015;33(43):5822-8.

10. Napolitano F, Gualdieri L, Santagati G, Angelillo IF. Knowledge and attitudes toward HPV infection and vaccination among immigrants and refugees in Italy. Vaccine. 2018;36(49):7536-41.

11. Larson HJ, Clarke RM, Jarrett C, Eckersberger E, Levine Z, Schulz WS, et al. Measuring trust in vaccination: A systematic review. Human Vaccines \& Immunotherapeutics. 2018;14(7):1599-609.

12. WHO Regional Office for Europe. Ukraine's efforts to stop measles outbreak continue as case total increases 2018 [updated 16/01/2018; cited 2018 26/07/2018]. Available from: http://www.euro.who.int/en/countries/ukraine/news/news/2018/01/ukrainesefforts-to-stop-measles-outbreak-continue-as-case-total-increases.

13. Larson HJ. The state of vaccine confidence. Lancet. 2018;392(10161):2244-6.

14. Korczynska MR. Rubella in Poland in 2015. Przeglad epidemiologiczny. 2017;71(3):319-26. 
15. WHO Europe. Europe observes a 4-fold increase in measles cases in 2017 compared to previous year 2018 [16/06/2018]. Available from: http://www.euro.who.int/en/media-centre/sections/press-releases/2018/europeobserves-a-4-fold-increase-in-measles-cases-in-2017-compared-to-previousyear.

16. European Centre for Disease Prevention and Control. Monthly measles and rubella monitoring report, January 2019. Stockholm: ECDC; 2019.

17. National Records of Scotland. Population by country of birth and nationality 2017. Edinburgh: Scottish Government; 2018.

18. Sim JA, Ulanika AA, Katikireddi SV, Gorman D. 'Out of two bad choices, I took the slightly better one': vaccination dilemmas for Scottish and Polish migrant women during the H1N1 influenza pandemic. Public Health. 2011;125(8):505-11.

19. Pollock KG, Tait B, Tait J, Bielecki K, Kirolos A, Willocks L, et al. Evidence of decreased HPV vaccine acceptance in Polish communities within Scotland. Vaccine. 2018;37(5):690-2.

20. Bielecki K, Kirolos A, Willocks LJ, Pollock KG, Gorman DR. Low uptake of nasal influenza vaccine in Polish and other ethnic minority children in Edinburgh, Scotland. Vaccine. 2018;37(5):693-7.

21. Brydak LB, Kosek AW, Nitsch-Osuch A. Influenza vaccines and vaccinations in Poland - past, present and future. Medical Science Monitor : International Medical Journal of Experimental and Clinical Research. 2012;18(11):RA166-RA71.

22. Ganczak M, Gil K, Korzeń M, Bażydło M. Coverage and Influencing Determinants of Influenza Vaccination in Elderly Patients in a Country with a Poor Vaccination Implementation. International Journal of Environmental Research and Public Health. 2017;14(6):665.

23. Ganczak M, Owsianka B, Korzen M. Factors that Predict Parental Willingness to Have Their Children Vaccinated against HPV in a Country with Low HPV Vaccination Coverage. Int J Environ Res Public Health. 2018;15(4).

24. Owsianka B, Ganczak M. Evaluation of human papilloma virus (HPV) vaccination strategies and vaccination coverage in adolescent girls worldwide. Przeglad epidemiologiczny. 2015;69(1):53-8, 151-5.

25. European Centre for Disease Prevention and Control. Poland: Recommended vaccinations [Web Page]. Stockholm2017 [updated November 13 2017. Available from: https://vaccineschedule.ecdc.europa.eu/Scheduler/ByCountry?SelectedCountryld=166\&IncludeChild AgeGroup=true\&IncludeAdultAgeGroup=true\&SelectedVersionld=45.

26. SZCZEPIENIA.INFO [Internet]. Polish National Institute of Public Health- National Institute of Hygiene. 2018 [cited 15/10/17]. Available from: http://szczepienia.pzh.gov.pl/en/. 
27. Braczkowska B, Kowalska M, Braczkowski R, Baranski K. Determinants of vaccine hesitancy. Przeglad epidemiologiczny. 2017;71(2):227-36.

28. Braczkowska B, Kowalska M, Barański K, Gajda M, Kurowski T, Zejda JE. Parental Opinions and Attitudes about Children's Vaccination Safety in Silesian Voivodeship, Poland. International Journal of Environmental Research and Public Health. 2018;15(4):756.

29. Jaroszewicz M. Migration from Ukraine to Poland: the trend stabilises. Warsaw: OSW - Centre for Eastern Studies; 2018.

30. Zarobkiewicz MK, Zimecka A, Zuzak T, Cieślak D, Roliński J, Grywalska E. Vaccination among Polish university students. Knowledge, beliefs and antivaccination attitudes. Human Vaccines \& Immunotherapeutics. 2017;13(11):2654-8.

31. Live births by country of birth of mother, Scotland, 2007, 2012, 2015 to 2017. Table 3.13 [Internet]. Scottish Government. 2018 [cited 29/12/18]. Available from: $\quad$ https://www.nrscotland.gov.uk/statistics-and-data/statistics/statistics-bytheme/vital-events/births.

32. Larson HJ, Jarrett C, Eckersberger E, Smith DMD, Paterson P. Understanding vaccine hesitancy around vaccines and vaccination from a global perspective: A systematic review of published literature, 2007-2012. Vaccine. 2014;32(19):2150-9.

33. Larson HJ, Jarrett C, Schulz WS, Chaudhuri M, Zhou Y, Dube E, et al. Measuring vaccine hesitancy: The development of a survey tool. Vaccine. 2015;33(34):4165-75.

34. Sawada M, Ueda Y, Yagi A, Morimoto A, Nakae R, Kakubari R, et al. HPV vaccination in Japan: results of a 3-year follow-up survey of obstetricians and gynecologists regarding their opinions toward the vaccine. International Journal of Clinical Oncology. 2018;23(1):121-5.

35. Corcoran B, Clarke A, Barrett T. Rapid response to HPV vaccination crisis in Ireland. The Lancet. 2018;391(10135):2103.

36. Jayaweera H. "Health of Migrants in the UK: What Do We Know?," Migration Observatory Briefing. COMPAS, University of Oxford, September 2014.

37. McCann A MP. Improving the Health of Migrants to Scotland: An update for Scottish Directors of Public Health. Glasgow: Scottish Public Health Network; 2016.

38. Sime D. 'I think that Polish doctors are better': Newly arrived migrant children and their parents 'experiences and views of health services in Scotland. Health \& Place. 2014;30:86-93.

39. Gorman DR, Porteous LA. Influences on Polish migrants' breast screening uptake in Lothian, Scotland. Public Health. 2018;158:86-92. 
40. Mrozek-Budzyn D, Kiełtyka A, Majewska R, Augustyniak M. Measles, mumps and rubella (MMR) vaccination has no effect on cognitive development in children - the results of the Polish prospective cohort study. Vaccine. 2013;31(22):2551-7.

41. Mrozek-Budzyn D. [The evolution of Polish immunization schedule during the last 10 years]. Przeglad epidemiologiczny. 2012;66(1):107-12.

42. Mrozek-Budzyn D, Majewska R, Kieltyka A, Augustyniak M. Lack of association between thimerosal-containing vaccines and autism. Przeglad epidemiologiczny. $2011 ; 65(3): 491-5$.

43. Ganczak M, Dmytrzyk-Danilow G, Karakiewicz B, Korzen M, Szych Z. Determinants influencing self-paid vaccination coverage, in 0-5 years old Polish children. Vaccine. 2013;31(48):5687-92.

44. Czarkowski MP, Hallmann-Szelinska E, Staszewska E, Bednarska K, Kondratiuk K, Brydak LB. Influenza in Poland in 2011-2012 and in 2011/2012 and 2012/2013 epidemic seasons. Przeglad epidemiologiczny. 2014;68(3):455-63, 559-65.

45. Jaroszewska K, Marciniak A, Gawlak M, Życińska K, Wardyn K, Nitsch-Osuch A. Perception of anti-vaccination movements by parents of young children. Postępy Nauk Medycznych. 2014;9:617-21.

46. Żuk P, Żuk P, Lisiewicz-Jakubaszko J. The anti-vaccine movement in Poland: The socio-cultural conditions of the opposition to vaccination and threats to public health. Vaccine. 2019;37(11):1491-4. 